University of New Hampshire

University of New Hampshire Scholars' Repository

2-27-2003

\title{
Investigations into free tropospheric new particle formation in the central Canadian arctic during the winter/spring transition as part of TOPSE
}

\author{
R J. Weber \\ Georgia Institute of Technology - Main Campus \\ D A. Orsini \\ Georgia Institute of Technology - Main Campus \\ B Wang \\ Georgia Institute of Technology - Main Campus \\ Eric Scheuer \\ University of New Hampshire - Main Campus, Eric.Scheuer@unh.edu \\ R. Talbot \\ University of New Hampshire, robert.talbot@unh.edu
}

See next page for additional authors

Follow this and additional works at: https://scholars.unh.edu/earthsci_facpub

Part of the Atmospheric Sciences Commons

\section{Recommended Citation}

Weber, R. J., et al. (2003), Investigations into free tropospheric new particle formation in the central Canadian arctic during the winter/spring transition as part of TOPSE, J. Geophys. Res., 108, 8357, doi:10.1029/2002JD002239, D4.

This Article is brought to you for free and open access by the Earth Sciences at University of New Hampshire Scholars' Repository. It has been accepted for inclusion in Earth Sciences Scholarship by an authorized administrator of University of New Hampshire Scholars' Repository. For more information, please contact Scholarly.Communication@unh.edu. 


\section{Authors}

R J. Weber, D A. Orsini, B Wang, Eric Scheuer, R. Talbot, Jack E. Dibb, Garry Seid, Linsey J. Debell, R L. Mauldin, E Kosciuch, C A. Cantrell, and Fred Eisele 


\title{
Investigations into free tropospheric new particle formation in the central Canadian arctic during the winter/spring transition as part of TOPSE
}

\author{
R. J. Weber, D. Orsini, and B. Wang \\ School of Earth and Atmospheric Sciences, Georgia Institute of Technology, Atlanta, Georgia, USA \\ E. Scheuer, R. W. Talbot, J. E. Dibb, G. K. Seid, and L. DeBell \\ Institute for the Study of Earth, Oceans, and Space, University of New Hampshire, Durham, New Hampshire, USA \\ R. L. Mauldin, E. Kosciuch, C. Cantrell, and F. Eisele \\ National Center for Atmospheric Research, Boulder, Colorado, USA \\ Received 26 February 2002; revised 13 June 2002; accepted 18 June 2002; published 22 January 2003.
}

[1] In this paper, we investigate the role of in situ new particle production in the central Canadian sub-Arctic and Arctic as part of the TOPSE experiment. Airborne measurements conducted primarily in the free troposphere were made from $50^{\circ}$ to $90^{\circ} \mathrm{W}$ longitude and $60^{\circ}$ to $85^{\circ} \mathrm{N}$ latitude during the period from February to May 2000. Data pertinent to this paper include 3-4 $\mathrm{nm}$ diameter $(\mathrm{Dp})$ particles, ultrafine condensation nuclei $(\mathrm{Dp}>3 \mathrm{~nm})$, fine particles $(0.2<\mathrm{Dp}<3 \mu \mathrm{m})$, and the possible nucleation precursor, sulfuric acid, and its precursor, sulfur dioxide. For data averaged over this period, most species showed little evidence for a latitudinal trend. Fine aerosol number concentrations, however, showed a slight increase with latitude. The evolution of various species concentrations over the period of the study show that fine particles also had a consistent temporal trend, increasing at all altitudes from February to May, whereas sulfur dioxide at the surface tended to peak in late March. Ultrafine condensation nuclei and 3-4 $\mathrm{nm}$ particles showed no temporal trends. Little evidence for in situ new particle production was observed during the study, except for one atypical event where $\mathrm{SO}_{2}$ concentrations were $3.5 \mathrm{ppbv}, 2$ orders of magnitude higher than typical levels. This paper cannot address the question of whether the observed condensation nuclei were produced in situ by a low particle production rate or transported from lower latitudes. INDEX TERMS: 0305 Atmospheric Composition and Structure: Aerosols and particles (0345, 4801); 0345 Atmospheric Composition and Structure: Pollution —urban and regional (0305); 0394 Atmospheric Composition and Structure: Instruments and techniques; KEYWORDS: Homogeneous nucleation, aerosols, nanoparticles, arctic haze

Citation: Weber, R. J., et al., Investigations into free tropospheric new particle formation in the central Canadian arctic during the winter/spring transition as part of TOPSE, J. Geophys. Res., 108(D4), 8357, doi:10.1029/2002JD002239, 2003.

\section{Background}

[2] Measurements have established that although remote, the Arctic is a major receptor of pollution from lower latitudes [e.g., Barrie, 1986; Heintzenberg, 1989; Radke et al., 1984; Rahn, 1981; Shaw, 1985]. Reaching a maximum in the dark months of late winter, the pollutants tend to dissipate in spring. Accumulation during Arctic winter has been attributed to a combination of the unique meteorology leading to long range transport of polluted air masses from lower latitudes, combined with low removal rates from a lack of both photochemical processing and significant deposition processes [Pacyna, 1995; Polissar et al., 1998,

Copyright 2003 by the American Geophysical Union. 0148-0227/03/2002JD002239
1999; Shaw, 1995; Sirois and Barrie, 1999; Xie et al., 1999]. In terms of aerosols, the most studied form of Arctic pollution is visibility degradation, referred to as Arctic Haze. These types of studies have shown that haze is most prevalent from about February to April and is composed largely of anthropogenic carbonaceous and sulfate components that likely originate from Eurasia and North America.

[3] Although not large enough to contribute to Arctic Haze, in situ sources of new particles within Arctic regions have also been investigated for some years. The process of homogeneous nucleation is of interest not only from a purely scientific basis, but the route in which low volatility gases undergo gas-to-particle conversion, homogeneous or heterogeneous nucleation, will influence the aerosol size distribution. Measurements suggest that under certain conditions new particles can be formed by homogeneous 
nucleation. Shaw [1989] reported episodically high condensation nuclei concentrations $\left(10^{4}\right.$ to $\left.10^{5} \mathrm{~cm}^{-3}\right)$ at a mountain site in Alaska when winds were of marine origin. Events were most frequent in the spring during intense sunlight, but before snowpack melt. Shaw speculated that these particles were from nucleation involving sulfuric acid and water, and not of anthropogenic origin. Brock et al. [1989] shows evidence for new particle production on the edge of haze layers observed during an August airborne study over Greenland and the North American Arctic.

[4] Extensive ship-based measurements of aerosol size distributions conducted in the late summer of 1991 at latitudes higher than $70^{\circ} \mathrm{N}$ as part of the International Arctic Ocean Expedition revealed evidence of nucleation. Periods of high sub-20 nm particle concentration were observed about $67 \%$ of the time and dominated the aerosol number distribution for about $10 \%$ of the time. This nanoparticle mode was thought to result from recent homogeneous nucleation [Covert et al., 1996]. Statistical analysis of the data suggested that the particles were produced at higher altitudes and mixed downward to the surface, and that the open sea was a possible source for the nucleation precursor gases [Wiedensohler et al., 1996].

[5] Continuous 1-year measurements of aerosol size distributions at a ground-based site in the Finnish Arctic $\left(67^{\circ} 46^{\prime} \mathrm{N}, 29^{\circ} 35^{\prime} \mathrm{E}\right)$ are reported by Pirjola et al. [1998]. This site experienced clean air of marine origin or polluted air from smelters to the East. Concentrations of particles greater than $\sim 15 \mathrm{~nm}$ ranged from about $100 \mathrm{~cm}^{-3}$ to 10,000 $\mathrm{cm}^{-3}$, with highest concentrations associated with pollution episodes. Nucleation events were associated with marine air masses and with smelter pollution events. Model results suggest that the marine events were not well explained by a binary $\mathrm{H}_{2} \mathrm{SO}_{4}-\mathrm{H}_{2} \mathrm{O}$ nucleation model whereas nucleation associated with the pollution events did appear to be consistent with binary predictions.

[6] This paper reports on airborne measurements of condensation nuclei and 3-4 nm particles made during the Tropospheric Ozone Production about the Spring Equinox (TOPSE) study. The primary objective of TOPSE was to investigate the spring-time tropospheric ozone maximum observed in mid- to high-latitudes over continental North America. Since the TOPSE instrumentation suite included measurements of sulfur dioxide $\left(\mathrm{SO}_{2}\right)$ and sulfuric acid $\left(\mathrm{H}_{2} \mathrm{SO}_{4}\right)$, species that have been linked to homogeneous nucleation [e.g., Weber et al., 1999b], the experiment provided a unique opportunity to investigate mechanisms of possible in situ particle sources. Thus our objective was to characterize the extent of new particle formation in the Arctic over the TOPSE measurement domain, and to investigate the nucleation mechanism by linking aerosol and TOPSE gas phase measurements. More complete descriptions of the TOPSE objectives and findings related to the mission's main goals can be found in the TOPSE special issue (Atlas et al, personal communication, 2002).

[7] TOPSE consisted of 7 deployments from January 20, 2000 to May 23, 2000. The dates and flight numbers for the various deployments are given in Table 1. All deployments began from the National Center for Atmospheric Research (NCAR) Research Aviation Facility (RAF) near Denver Colorado. The C-130 research aircraft would fly to Winnipeg, Manitoba, Canada in route to bases of operations at
Table 1. Dates and Flight Numbers for the Seven TOPSE Deployments, Each Involving Round-Trip Missions From the NCAR Research Aviation Facility in Colorado to Bases of Operation at Churchill, Manitoba, Canada or Thule, Greenland

\begin{tabular}{cccc}
\hline Deployment & Julian Days & Dates & Flight Numbers \\
\hline 1 & $35-40$ & $02 / 04-02 / 09$ & $5-8$ \\
2 & $52-58$ & $02 / 21-02 / 27$ & $9-13$ \\
3 & $65-68$ & $03 / 05-03 / 08$ & $14-17$ \\
4 & $78-86$ & $03 / 18-03 / 26$ & $18-23$ \\
5 & $93-102$ & $04 / 02-04 / 11$ & $24-30$ \\
6 & $114-121$ & $04 / 23-04 / 30$ & $31-36$ \\
7 & $136-144$ & $05 / 15-05 / 23$ & $37-42$ \\
\hline
\end{tabular}

Churchill, Manitoba and Thule, Greenland. Flight paths are shown in Figure 1. Typically, 2 to 3 research flights were conducted from Churchill or Thule per deployment. By spacing the deployments over time, the mission could investigate changes in the composition of pertinent tropospheric species during the transition from complete darkness of Arctic winter to continuous sunlight of spring, following polar sunrise in early March.

\section{Instrumentation}

[8] As part of the TOPSE experiment, the instrumentation payload of the National Science Foundation's C-130 research aircraft included capabilities for measurements of $\mathrm{SO}_{2}, \mathrm{H}_{2} \mathrm{SO}_{4}, 3-4 \mathrm{~nm}$ particles, ultrafine condensation nuclei (UCN), and wing mounted optical probes measuring spectra of particles larger than roughly $0.2 \mu \mathrm{m}$ diameter. These instrumentation are discussed briefly, however, the focus is on the 3-4 nm particle measurements since these particles are used as indicators of in situ particle production.

[9] Ultrafine condensation nuclei and 3-4 nm particles were measured simultaneously with a modified ultrafine condensation particle counter (UCPC). The instrument is a commercial ultrafine condensation particle counter (TSI 3025, TSI Inc, St. Paul MN) in which the laser optics have been replaced by a white light system [Dick et al., 2000; Marti et al., 1996] to permit sizing nanoparticles by pulse height analysis (PHA) [Saros et al., 1996; Weber et al., $1998 \mathrm{c}$ ]. Condensation nuclei counters are based on exposing ambient particles to a supersaturated vapor, typically butanol, causing the particles to grow to sizes where they can be detected optically. In the ultrafine condensation particle counter, all particles larger than approximately 3 nm activate, grow, and are detected. Although, most particles grow to similar fine size, particles between roughly 3 and $10 \mathrm{~nm}$ diameter reach different final sizes that are related to their initial size [Saros et al., 1996]. With an appropriate optical detector in the ultrafine condensation particle counter, the final drop size can be determined from photodetector pulse heights and, based on laboratory calibrations, related to the original particle size. Thus by simply counting all photodetector pulses, the concentration of all particles larger than $3 \mathrm{~nm}$ is determined, and by recording pulse heights, concentrations of sub-10 nm particles can also be measured simultaneously. The data acquisition system records total ultrafine particle concentrations (all particles larger than nominally $3 \mathrm{~nm}$ diameter) at $1 \mathrm{~Hz}$, and nanoparticle concentrations $(3-10 \mathrm{~nm}$ diameter) integrated over $60 \mathrm{~s}$. 


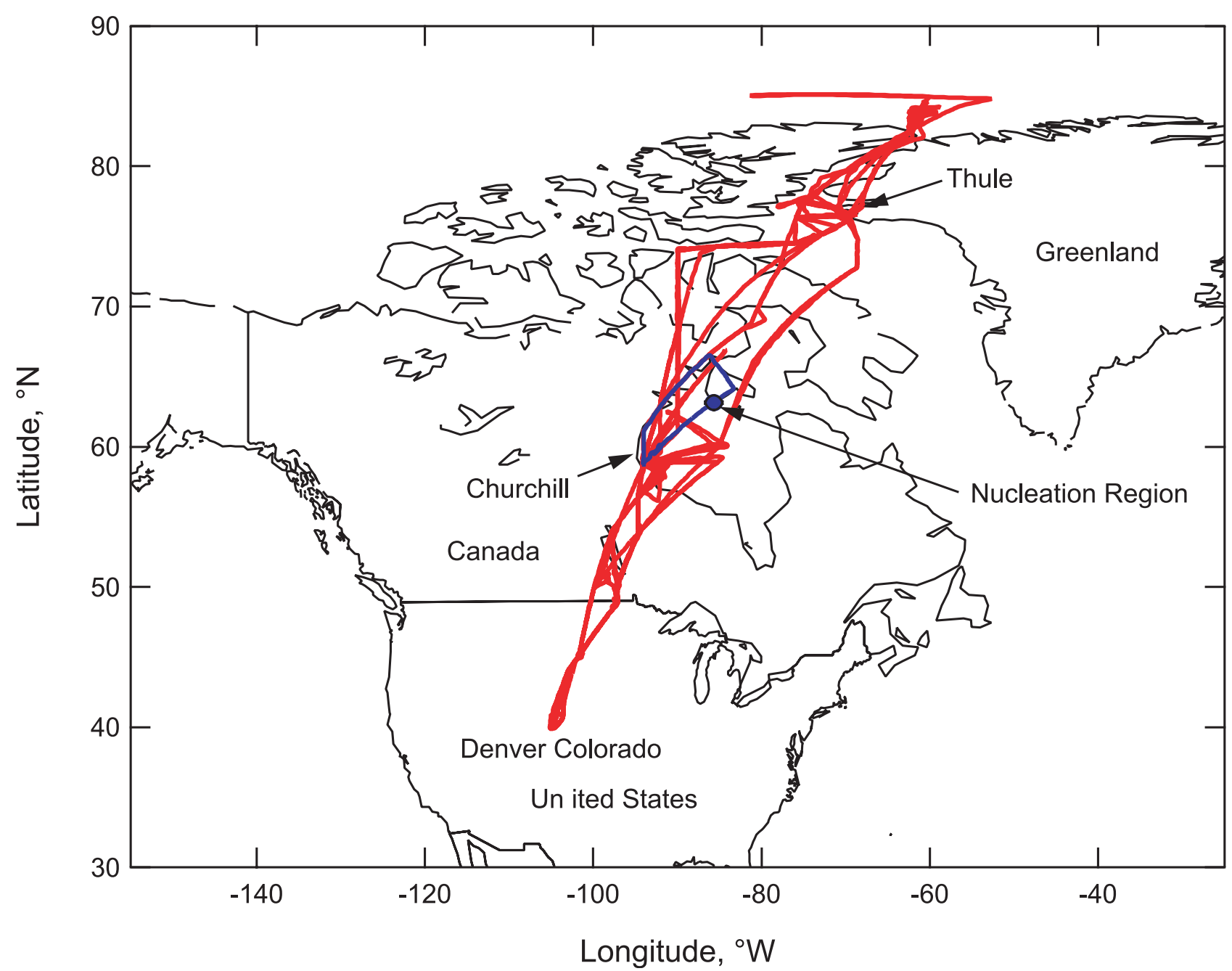

Figure 1. Flight paths for the TOPSE missions with the flight path and location of the nucleation event discussed in Figures 5 and 6 identified.

[10] The pulse height data from the $3-10 \mathrm{~nm}$ particles are further analyzed to determine the concentrations of nominally 3-4 $\mathrm{nm}$ particles. Measurements of these 3-4 $\mathrm{nm}$ particles are used to investigate new particle formation. The assumption is that these particles are exclusively formed by homogeneous nucleation; a reasonable assumption if the measurements are not influenced by large sources of fresh combustion products that may produce primary nanoparticles. The technique has been used extensively in other studies to investigate new particle formation [Weber et al., 2001a, 2001b, 1996, 1995, 1998b, 1999b]. A limitation with this approach, however, is that newly formed particles have sizes near 1 to $1.5 \mathrm{~nm}$ and are significantly smaller than the instrument lower size detection limit of about 2.7 $\mathrm{nm}$. This means that aged particles that have grown to roughly $3 \mathrm{~nm}$ are detected instead of those freshly formed. In regions of vigorous nucleation where condensable gas concentrations are high, growth will be fast and the $3-4 \mathrm{~nm}$ particles detected will have formed recently. However, in more pristine regions where condensable gas concentrations are low, the nanoparticles can be well aged. This would confound interpretations on nucleation mechanisms based on 3-4 nm particle concentrations. This is, however, one of the best approaches currently available since the pulse height analysis technique permits measuring concentrations in a narrow size range near $3 \mathrm{~nm}$. Other approaches, for example, measure concentrations of particles in the 3-10 $\mathrm{nm}$ size-range; a measurement that by including larger sizes is influenced even more by aged particles.

[11] The pulse height ultrafine condensation particle counter was operated unattended throughout the TOPSE study. Any required maintenance and downloading of data was performed after each TOPSE deployment at the NCAR facilities in Colorado. Aerosol sampling was from a simple forward-facing inlet in which the flow was maintained at a constant value of $13.51 \mathrm{~min}^{-1}$ via a critical orifice. This resulted in a velocity at the inlet tip of $\sim 115 \mathrm{~m} \mathrm{~s}^{-1}$. Since the inlet flow was not adjusted, and the aircraft speed typically ranged from 100 to $160 \mathrm{~m} \mathrm{~s}^{-1}$, depending on altitude, sampling was only nominally isokinetic. From this inlet, the aerosol was transported by a $0.64 \mathrm{~cm}(1 / 4$ inch) copper tube to the pulse height-UCPC detector. At the entrance to the detector, the sample flow was extracted from the centerline of the transport flow with a $0.32 \mathrm{~cm}(1 / 8$ inch) diameter tube. The pulse height-UCPC detector flow system was modified to run off an external pump versus the 
smaller pump supplied with the commercial instrument (TSI 3025 UCPC, TSI Inc St Paul MN). This was done to minimize fluctuations in the flow due to pressure variations in the inlet. Because of the internal flow geometry of the UCPC, these fluctuations can severely degrade the instruments' performance.

[12] The NCAR C130 is equipped with a variety of aerosol detectors, including a condensation nuclei counter (TSI 3760, St Paul MN) operating within the aircraft cabin, and wing-mounted optical probes (PMS, Boulder CO). The condensation nuclei counter is of interest since it provided comparisons with our ultrafine particle counter (UCPC). The optical probe data provided concentrations of particles with diameters greater than roughly $0.2 \mu \mathrm{m}$.

[13] The RAF CN counter measured all particles larger than nominally $15 \mathrm{~nm}$ diameter and sampled from an actively controlled isokinetic inlet. The aerosol transport flow system had been modified in an attempt to exclude spurious particles formed by cloud droplets shattering on the inlet (A. Schanot, personal communication, 2001). This type of artifact is discussed in Weber et al. [1998a] and avoided in this study by removing all data collected during in-cloud sampling.

[14] Good agreement was found between the pulse height-UCPC and the NCAR condensation nuclei counter. In Figure 2 the instruments are compared for measurements made during deployment 4, for flights, 20, 21, and 22 . These flights were chosen because there were few sub-10 $\mathrm{nm}$ particles detected, thus minimizing the difference in the lower size detection limits of the two instruments. The correlation $\left(\mathrm{r}^{2}\right)$ is 0.93 and the linear regression fit is 1 to

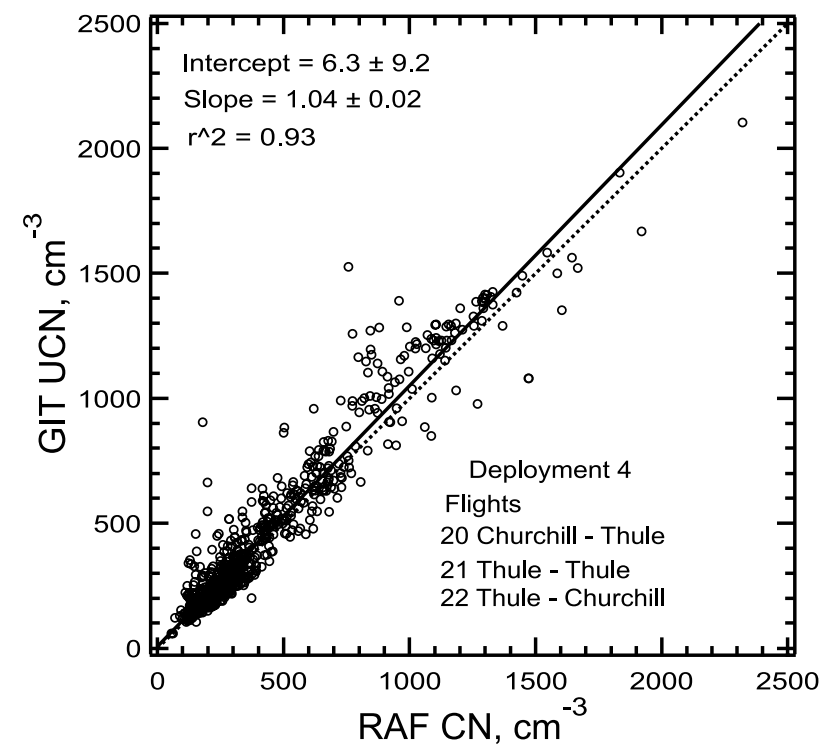

Figure 2. Comparison of two independent instruments for measuring total particle concentrations from separate inlets on the NSF C-130 research aircraft. UCN are all particles larger than $3 \mathrm{~nm}, \mathrm{CN}$ all particles larger than $15 \mathrm{~nm}$. Sampling in the vicinity of airports is excluded. These flights were chosen for their low concentrations of 3-10 nm particles, thereby minimizing instrument lower detection limit differences. Uncertainties in the linear curve fit coefficients are $95 \%$ confidence intervals.
Table 2. Summary of Instrumentation Pertinent to This Study ${ }^{\mathrm{a}}$

\begin{tabular}{lll}
\hline \multicolumn{1}{c}{ Instrument/Species } & \multicolumn{1}{c}{ Method } & \multicolumn{1}{c}{ Size Range } \\
\hline Gases & Mist Chamber & - \\
$\mathrm{SO}_{2}$ & $\begin{array}{l}\text { Chem. Ionization Mass } \\
\mathrm{H}_{2} \mathrm{SO}_{4}\end{array}$ & - \\
& $\quad$ Spectrometry & \\
Particles & Pulse height analysis- & $3-4 \mathrm{~nm}$ \\
Pulse Height UCPC & $\quad$ condensational growth & \\
& Condensational growth & $\mathrm{Dp}>3 \mathrm{~nm}^{\mathrm{b}}$ \\
Pulse Height UCPC & Condensational growth & $\mathrm{Dp}>15 \mathrm{~nm}$ \\
NCAR CPC & Optical counter & $0.2-3 \mu \mathrm{m}$ \\
PCASP (Fine Particles) & Optical counter & $2-47 \mu \mathrm{m}$ \\
FSSP-100 & Optical counter & $0.3-20 \mu \mathrm{m}$ \\
FSSP-300 &
\end{tabular}

${ }^{\mathrm{a}}$ More details are provided in the instrumentation section.

${ }^{\mathrm{b}} \mathrm{Dp}$ stands for particle diameter.

1 within a $95 \%$ confidence interval. This good agreement is consistent with intercomparisons of condensation nuclei counters deployed in the first Aerosol Characterization Experiment (ACE 1) where, for example, a similar pulse height UCPC and the same NCAR condensation nucleus counter had a $r^{2}$ of 0.86 [Weber et al., 1999a]. The ACE 1 intercomparison showed that airborne measurements of condensation nuclei are fairly insensitive to the specific aerosol sampling methodology employed, however this is not true for nanoparticles due to their high mobility resulting in significant transport losses. The approach of extracting a sample from the centerline of the transport flow near the UCPC is an attempt to minimize nanoparticle losses, however it is estimated that $3-4 \mathrm{~nm}$ particles are undermeasured by at least $50 \%$. Combined with our simplistic approach of determining 3-4 $\mathrm{nm}$ particle concentrations from the measured pulse height distributions, reported 3-4 $\mathrm{nm}$ particle concentrations should be viewed as only estimates of ambient concentrations, and thus as an indicator of possible recent production.

[15] Wing-mounted optical probes recorded aerosol size distributions. These included a Passive Cavity Aerosol Spectrometer Probe (PCASP), Forward Scattering Spectrometer Probe (FSSP) 100, and FSSP 300 (all from PMS, Boulder, Colorado). Combined, the instruments provide size distributions spanning particle diameters from roughly 0.2 $\mu \mathrm{m}$ to $50 \mu \mathrm{m}$. In this work we use measurements of large cloud liquid/ice concentrations inferred from the FSSP-100 ( 2 to $47 \mu \mathrm{m}$ ) to exclude in-cloud data. The PCASP measurement includes particles between approximately 0.2 and 3 $\mu \mathrm{m}$ diameter. Number concentrations or these accumulation mode (fine) aerosols are used as an indicator of haze particles, as done in other work [Dreiling and Friederich, 1997]. The data are also used to estimate the aerosol surface area. This approach, however, under-measures particle surface area concentrations since particles smaller than $0.2 \mu \mathrm{m}$ can be a significant fraction of the total surface area. In addition, it is known that the PCASP heats, and thus dries the aerosol during measurement, also resulting in an under measured ambient surface area concentration. This is not corrected since in this analysis PCASP-derived surface areas are only used as a rough estimate of the actual aerosol surface area concentration.

[16] Other measurement techniques used in this analysis include $\mathrm{H}_{2} \mathrm{SO}_{4}$ gas by chemical ionization mass spectrom- 
etry [Eisele, 1989; Eisele and Tanner, 1993] and $\mathrm{SO}_{2}$ and fine sulfate aerosol (diameters less than $2.7 \mu \mathrm{m}$ ) captured into water by a mist chamber and measured via ion chromatography [Cofer et al., 1985; Scheuer et al., 2002]. Table 2 summarizes the various instruments operating principles and measurement size ranges, where applicable.

\section{Observations and Discussion}

\subsection{Trends}

[17] In the following analysis, trends in condensation nuclei and fine aerosol concentrations, and the possible nucleation precursor gases $\mathrm{H}_{2} \mathrm{SO}_{4}$, and its primary precursor $\mathrm{SO}_{2}$, are investigated. Comparisons between condensation nuclei and fine particles are of interest since their concentrations tend to be influenced by different processes. Condensation nuclei concentrations are affected largely by new particle production, whereas the fine aerosols tend to accumulate low volatility gaseous species and are also of interest since they contribute to Arctic haze. The data are reported per standard volume of air (e.g., 1 atmosphere and $0^{\circ} \mathrm{C}$ ), with the exception of $\mathrm{SO}_{2}$ and sulfate aerosol, which are reported as mixing ratios. Trends are analyzed by calculating median concentrations. Other statistical measures for central tendencies can be used, such as geometric or arithmetic means. Analysis of the various means has shown that in this case, the type of mean used does not greatly influence the conclusions. We have chosen to use the median since the distributions tends to be skewed to larger sizes, and the median is less sensitive than the mean to these points. The geometric mean cannot be applied for $3-4 \mathrm{~nm}$ particle statistics since these concentrations are often zero. The spread in the distributions about the median is shown by the standard error, which is the standard deviation divided by the square root one-minus the number of data points. Standard deviations are not plotted since they tend to be large and would obscure the plots.

\subsubsection{Latitudinal Variations}

[18] Median latitudinal concentration variations of $\mathrm{SO}_{2}$, $\mathrm{H}_{2} \mathrm{SO}_{4}, 3-4 \mathrm{~nm}$ particles, ultrafine condensation nuclei, and fine particles, for data over the complete study, are shown in Figure 3. Here all data are plotted from the NCAR operations base near Denver to the most northern latitudes investigated. Also plotted is the median aircraft altitude, indicting that most measurements were made in the 4 to 7 $\mathrm{km}$ altitude range. In this case, the lack of sufficient data at lower altitudes for some latitude ranges prohibits a more detailed analysis by segregating data into various altitude bins.

[19] As expected, many species show highest concentrations in the vicinity of the populated areas where the aircraft landed. Ignoring these localized emissions, for this broad range in latitudes, only fine aerosol number concentrations have any evidence of a latitude trend. This trend is not an artifact of converting concentrations to standard conditions combined with temperatures dropping with increasing latitude since conversion to standard pressure and ambient temperature does not change the trend. The higher concentrations at the more northern latitudes may be evidence of Arctic Haze.

[20] A feature in the latitude trends for $\mathrm{SO}_{2}$ and 3-4 nm particles is the variability caused by episodic encounters with high concentrations. This was recorded at mainly lower latitudes. For $\mathrm{SO}_{2}$, the largest episode encountered, labeled $A$ in Figure 3, was detected north of Churchill on Flight 16. This episode appears to be the only region in the Arctic, during TOPSE, where there was clear evidence of recent and significant rates of new particle formation detected away from the populated areas. The episode is investigated in more detail in a following section.

\subsubsection{Temporal Changes During Winter-Spring Transition}

[21] A unique feature of the TOPSE experiment was that it occurred over an extended period of time spanning the winter to spring transition, the period when the winter buildup of Arctic pollution begins to dissipate and photochemistry increases.

[22] Figure 4 shows the time-variation of $\mathrm{SO}_{2}, \mathrm{H}_{2} \mathrm{SO}_{4}$, 3-4 $\mathrm{nm}$ particles, ultrafine condensation nuclei, and fine aerosol concentrations for data binned into 3 altitude ranges. An attempt has been made to remove the local influences from the "populated" areas of Churchill and Thule. Only measurements at latitudes greater than $60^{\circ} \mathrm{N}$ are included since our interests are in nucleation at the higher latitudes. This also tends to remove most of the influence from Churchill, and based on Figure 3, covers the latitudinal range where aerosol concentrations tend to be most similar. Median concentrations are calculated for a given altitude range for data collected during each of the seven deployments (see Table 1). Because of aircraft electrical problems that resulted in the sacrifice of our unmanned instrument, there is little ultrafine condensation nuclei data for the first two deployments and averages were not calculated for that period.

[23] Temporal $\mathrm{SO}_{2}$ trends, shown in Figure 4a, are dominated by the large $\mathrm{SO}_{2}$ peak observed during Flight 16 as part of the third deployment in March. This peak corresponds to the event identified as $A$ in Figure 3. Aside from this aberrant event, $\mathrm{SO}_{2}$ concentrations at all altitudes follow a similar trend. High during the first deployment in the beginning of February, dropping during the next deployment, than increasing to maximum values in late March and then a fairly consistent decrease to the end of the study. Through March and April, $\mathrm{SO}_{2}$ concentrations were significantly higher at the surface compared to higher altitudes. Note that the aberrant $\mathrm{SO}_{2}$ events, however, were observed in the $2-5 \mathrm{~km}$ altitude range.

[24] $\mathrm{H}_{2} \mathrm{SO}_{4}$ concentrations were most often highest in the $0-2 \mathrm{~km}$ altitude range, except for the measurements associated with the $\mathrm{SO}_{2}$ event $(2-5 \mathrm{~km}$ peak at the beginning of March). The data suggest a consistent increase in surfacelevel $\mathrm{H}_{2} \mathrm{SO}_{4}$ concentrations throughout the study until the last deployment, at which point the concentration falls off.

[25] 3-4 $\mathrm{nm}$ particle concentrations tend to fluctuate a great deal and are generally very low showing no trend. Unlike all other species, ultrafine condensation nuclei concentrations were generally lowest at the lower altitudes. There may be evidence for a slight increase in ultrafine condensation nuclei concentrations with time for all altitudes, (Figure 4d), but clearly it is not dramatic. The ultrafine condensation nuclei, and especially the 3-4 nm particle, variability appear to be driven in large part by encounters with episodic events. Note that the anomalous $\mathrm{SO}_{2}$ event is not seen in the $3-4 \mathrm{~nm}$ particle data because, 
6 i

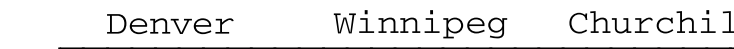

Thule

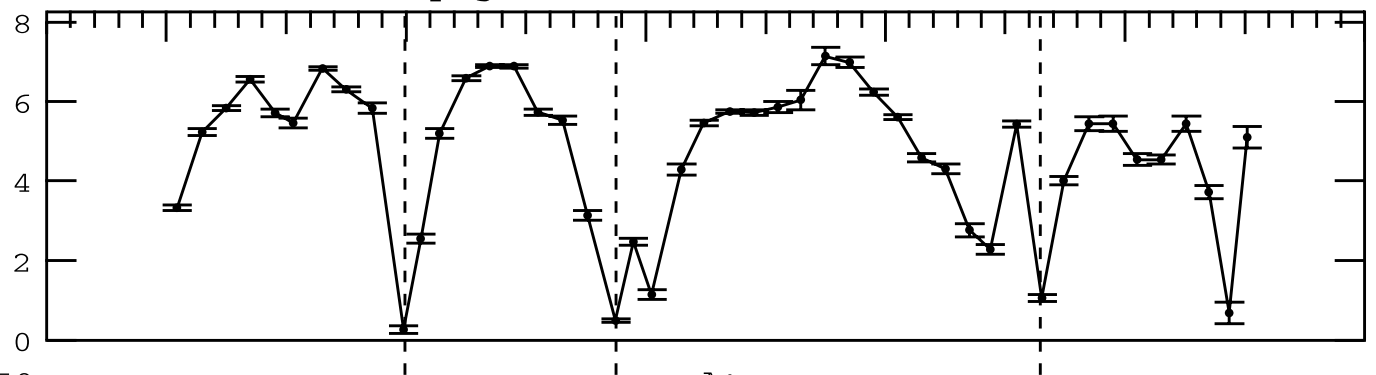

U

in

50
40
30
20
10
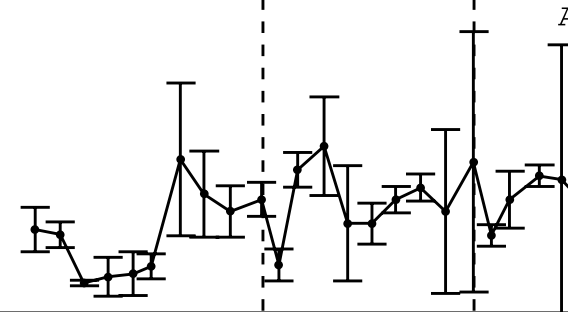

X

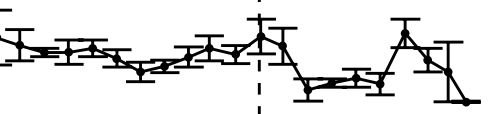

(1.5

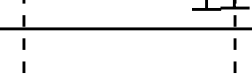

m
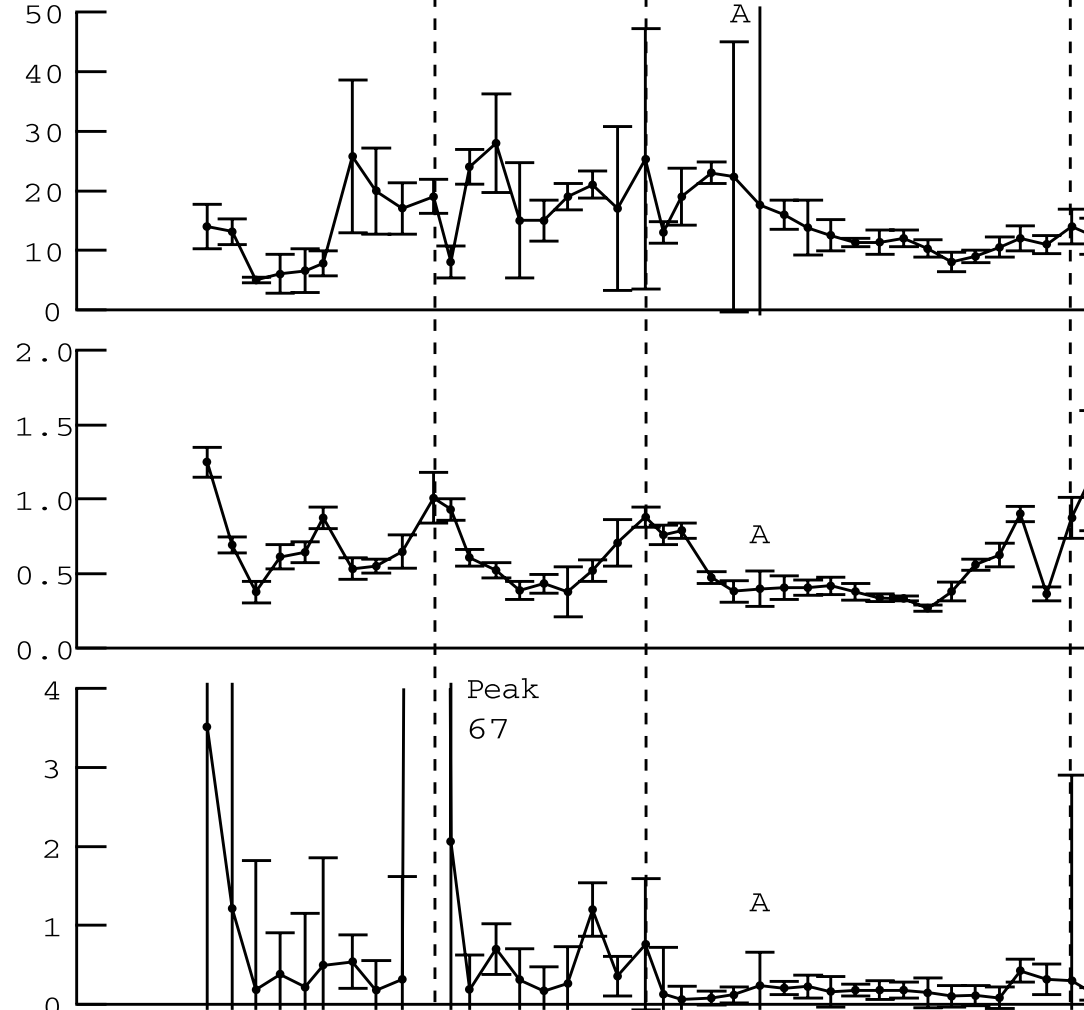

I

。
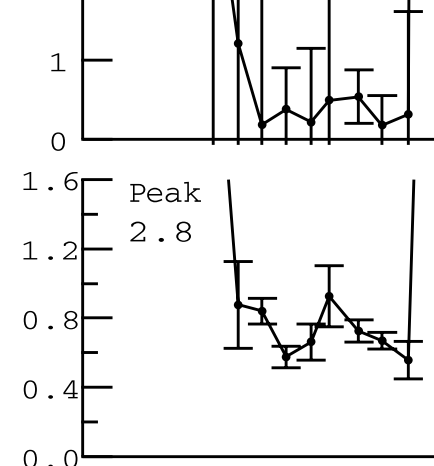

(1)
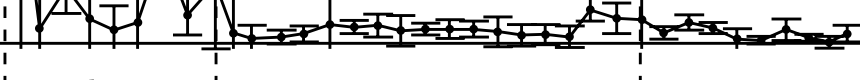

mo

$x$

$$
\text { }
$$

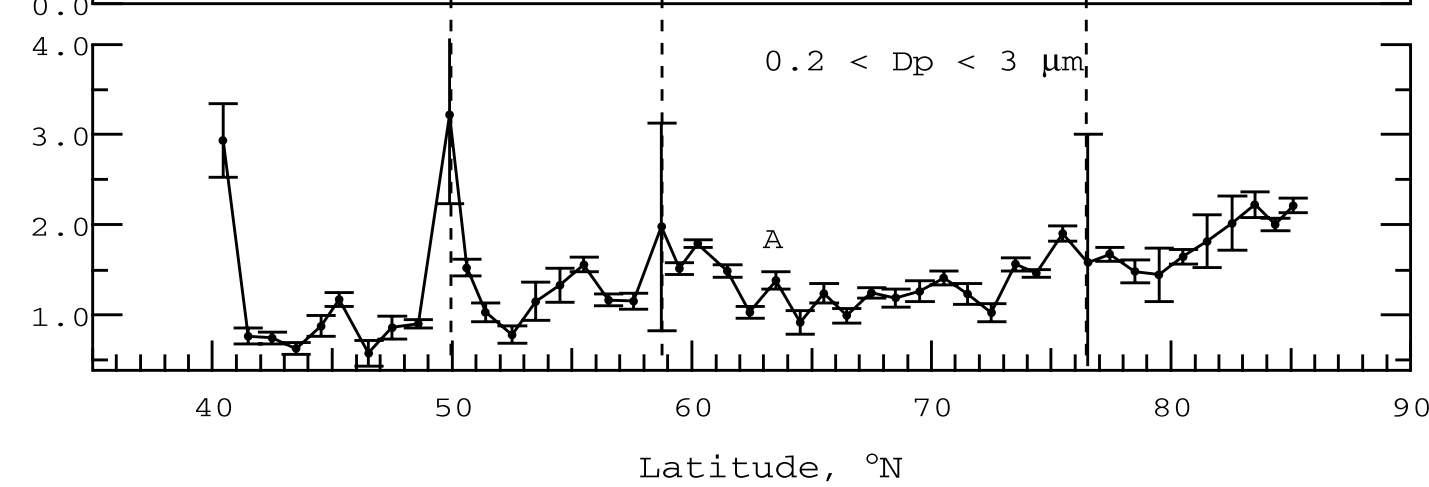

Figure 3. Median aircraft altitude, $\mathrm{SO}_{2}, \mathrm{H}_{2} \mathrm{SO}_{4}, 3-4 \mathrm{~nm}$ particles, $\mathrm{UCN}$, and fine particles averaged over 1-degree latitude steps. All concentration data, except for $\mathrm{SO}_{2}$, are at 1 atmosphere and $0^{\circ} \mathrm{C}$. "Error bars" are the standard error of the distribution and are shown to indicate the range in the data. They are not a measurement uncertainty. 


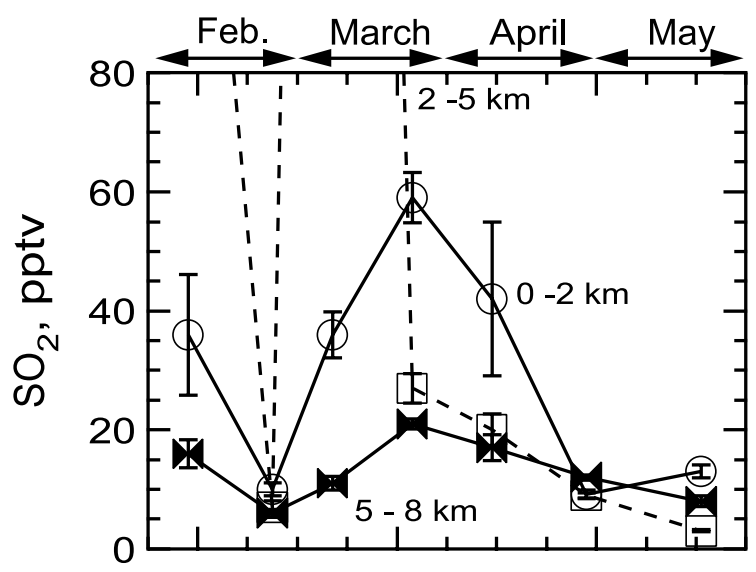

a.

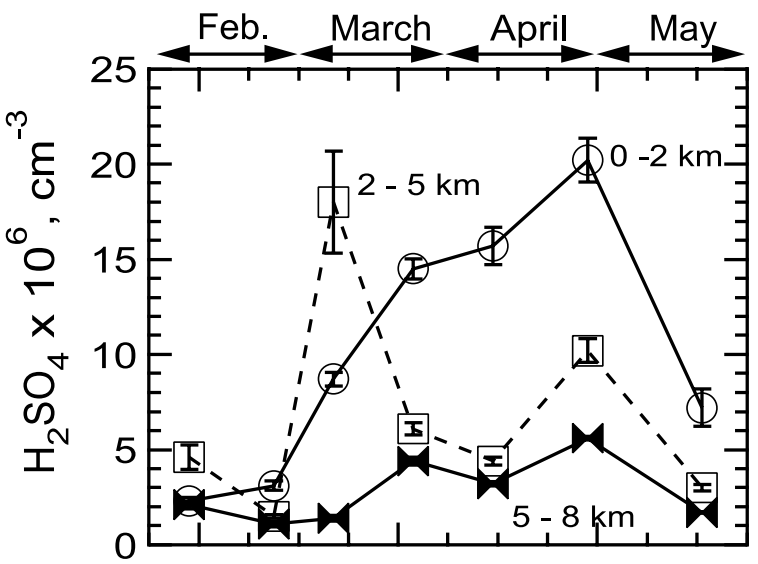

b.

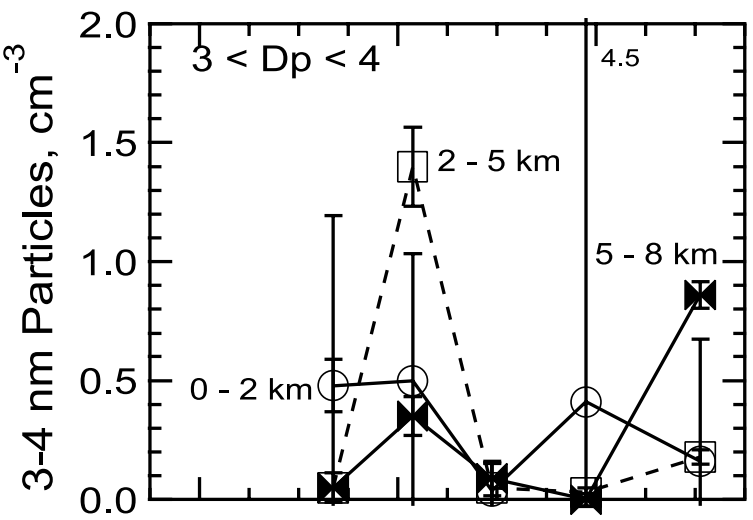

C.

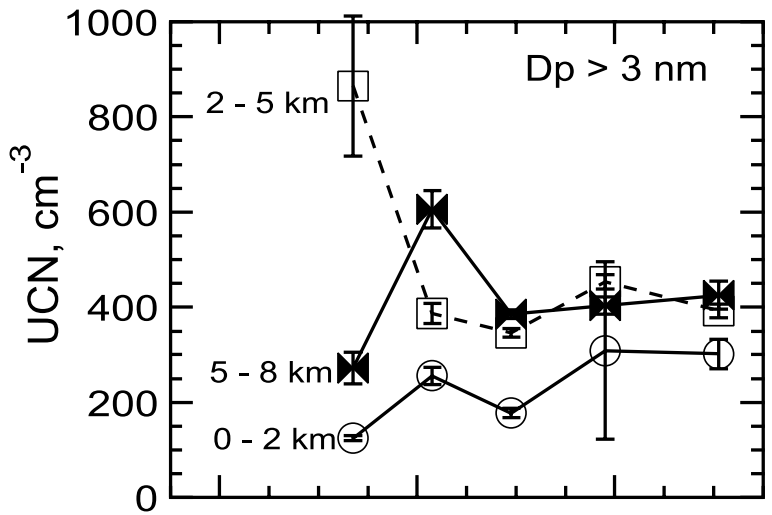

d.

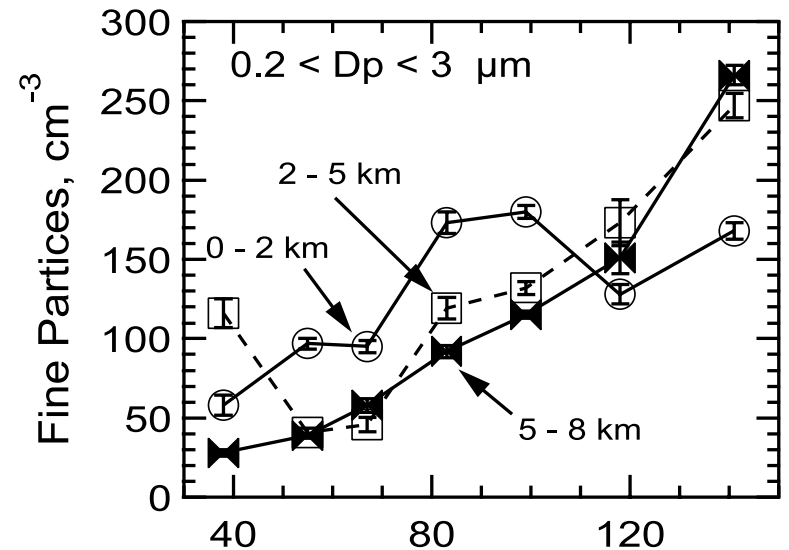

e.

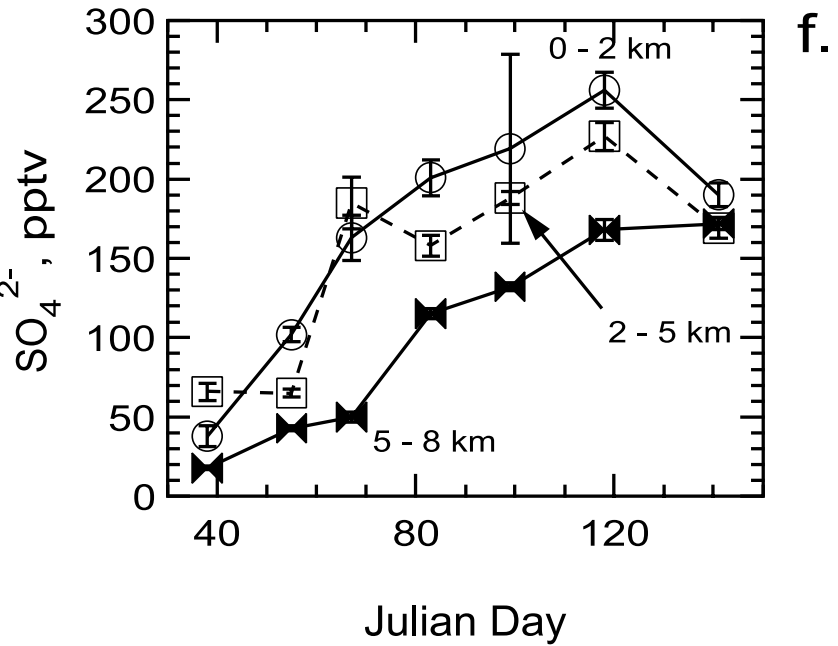

Figure 4. Temporal trends in various species measured during the TOPSE Experiment. Data points are the median concentrations for each deployment for latitudes greater than $60^{\circ} \mathrm{N}$. Local influences from Churchill and Thule are not included. "Error bars" are the standard error of the distribution and are shown to indicate the range in the data. They are not a measurement uncertainty.

as shown later, the effect on nanoparticles was spatially limited and is washed out by the averaging.

[26] Number concentrations of fine particles $(0.2$ to 3 $\mu \mathrm{m})$, shown in Figure 4e, have a very different trend than the ultrafine condensation nuclei. Fine particle concentrations are often higher at lower altitudes and clearly increase from February to May. During this time the concentrations increased by about a factor of 5. Previous Arctic studies have shown that there is often little correlation between fine-mode haze particles and condensation nuclei [Dreiling and Friederich, 1997] since the haze layers tend to be dominated by particles larger than $0.1 \mu \mathrm{m}$ and condensation nuclei is comprised mainly of smaller particles. Highest fine (haze) particle concentrations at the surface are consistent with reports from earlier studies. There is also evidence of a ripple in the lowest altitude trends in late March and early 
April, the time when $\mathrm{SO}_{2}$ also peaked (apart from the anomalous event).

[27] For comparison to the fine aerosol number concentration, fine sulfate aerosol temporal trends are shown in Figure $4 \mathrm{f}$. Fine sulfate aerosol trends generally agree with the fine aerosol number concentrations; highest at the surface and increasing with time. However, sulfate concentrations appear to begin to drop by the end of April. This difference may be due to difference in the two measurements; one is a number concentration and the other a mass concentration measurement. Thus the fine aerosol measurements are dominated by the smaller size particles, $(\sim 0.2 \mu \mathrm{m}$ diameter), whereas the mass measurement are more likely dominated by larger particles (near $1 \mu \mathrm{m}$ diameter).

[28] A much more detailed analysis of the TOPSE sulfate data is given by Scheuer et al. [2002]. In that study, sulfate trends based on data averaged over all latitudes greater than $50^{\circ} \mathrm{N}$ (i.e., extending to lower latitudes than shown here), indicate a clear decrease in sulfate concentrations beginning in early April. The differences between the two results suggest that the dissipation in pollution progresses northward as the year advances.

[29] The temporal data observed over this time and latitude range reflect changes in various processes, including the combined effects of decreasing advection of pollution from lower latitudes with time, and increasing photochemical processing, either in situ or during transport from lower latitudes. There may be some consistency between the temporal trends in $\mathrm{SO}_{2}, \mathrm{H}_{2} \mathrm{SO}_{4}$, fine aerosol number, and sulfate aerosol concentration data. For example, increased conversion of $\mathrm{SO}_{2}$ to sulfate, possibly due to increased actinic fluxes, following polar sunrise in early March, and/or greater heterogeneous conversion within clouds, may contribute to the drop in $\mathrm{SO}_{2}$, and increase in $\mathrm{H}_{2} \mathrm{SO}_{4}$, fine aerosol sulfate, and increase in numbers of fine particles. The latter due to growth of smaller particles into the measurement size range $(0.2 \mu \mathrm{m}$ to $3 \mu \mathrm{m})$ from heterogeneous condensation.

[30] With regards to our interest into new particle production in this region, the observed increasing trend in surface-level $\mathrm{H}_{2} \mathrm{SO}_{4}$ and fine aerosols, and a lack of similar trends in ultrafine condensation nuclei and 3-4 nm particle concentrations suggest that there is a general lack of significant rates of new particle formation in this region. This is despite possible evidence for increased gas-toparticle conversion during this time. No evidence for a consistent and significant source of new particles following polar sunrise is observed.

\subsection{Prevalence of 3-4 nm Particles at Low Concentrations}

[31] Trends in 3-4 $\mathrm{nm}$ particle distributions indicated that low concentrations of these particles were often detected in the Arctic regions investigated during this study (Figures 3 and 4). As a single particle counter, the pulse height-UCPC can detect zero $3-4 \mathrm{~nm}$ particle concentrations, and in many of our other studies these concentrations are often zero. However in TOPSE, calculated 3-4 nm particle frequency distributions for latitudes greater than $60^{\circ} \mathrm{N}$ show that nonzero concentrations of nanoparticles were observed approximately $75 \%$ of the time, concentrations greater than $1 \mathrm{~cm}^{-3}$, $25 \%$ of the time, and greater than $10 \mathrm{~cm}^{-3}$, only $\sim 2 \%$ of the time. (This excludes measurements in the vicinity of the populated regions of Churchill and Thule). Compared to other studies, this is a higher frequency than what was observed in the remote tropics [Weber et al., 2001b] but less than at a clean continental site [Weber et al., 1997]. However, the observation of non-zero 3-4 nm particle concentrations $75 \%$ of the time is interesting given that so few clear episodes of new particle formation were detected during the study.

[32] Our interest is whether these particles are aged or recently formed in situ. The uniformity of the latitudinal and temporal trend data suggest aged particles. As done in other studies to assess 3-4 $\mathrm{nm}$ particle age [Weber et al., 2001b, 1997], the characteristic lifetime (e-folding time) of a 3-nm particle via loss through scavenging onto the preexisting particles is estimated based on the aerosol surface area concentration. In this case the analysis is handicapped by uncertainties in the aerosol surface area. Based on PCASP size distributions $(0.2<\mathrm{Dp}<3 \mu \mathrm{m})$, surface areas were typically near $10 \mu \mathrm{m}^{2} \mathrm{~cm}^{-3}$ (mean of 9 and median of 6 $\mu \mathrm{m}^{2} \mathrm{~cm}^{-3}$ ). At these surface area concentrations, the characteristic life times of a 3-4 nm particle is of the order of 20 hrs in the presence of surface areas of $5 \mu^{2} \mathrm{~cm}^{-3}$, and 10 hrs when surface areas are $10 \mu \mathrm{m}^{2} \mathrm{~cm}^{-3}$. The observed 3-4 $\mathrm{nm}$ particle concentrations, following decay due to scavenging, depends on the particle history, especially their initial concentrations and the particle surface area concentrations exposed prior to detection. Given that in general, loss mechanisms in the Arctic during the winter and early spring are slow, a factor accounting for the build up of Arctic haze, the prevalence of low 3-4 nm particle concentrations may also result from a similar lack of strong sinks. In this case the particles would most likely have been formed at lower latitudes closer to their precursor sources.

[33] Alternatively, low levels of 3-4 nm particles could be from a low, fairly wide spread, particle production rate. A previous study in a remote marine region, however, showed no evidence for a low particle production rate [Weber et al., $2001 \mathrm{~b}]$. The fact that in situ particle production, or the lack there of, cannot be clearly identified is due to the lower size detection limitations with current aerosol instrumentation. However, from the TOPSE 3-4 nm particle data, we can conclude that evidence for large in situ particle production events were rarely observed. The one exception to this is an episode associated with the highest $\mathrm{SO}_{2}$ concentrations of the study.

\subsection{A 3-4 nm Particle Episode Associated With Enhanced $\mathrm{SO}_{2}$ Concentrations}

[34] Although rare, a unique region of high 3-4 nm particle concentrations associated with expected nucleation precursor gases was detected during the study. Encountered on a round-trip flight based out of Churchill (Deployment 3, Flight 16, Julian day 67), and identified in Figure 1 and Figure 3 by $A$, this event was associated with a region of highest $\mathrm{SO}_{2}$ concentrations measured in the Arctic during TOPSE.

[35] The flight involved an elongated loop with the first leg heading northeast roughly along the coast of Hudson Bay. A sharp turn to the South East was made near Repulse Bay and then a southwest turn leading to a straight flight path skirting the south edge of Southampton Island and 


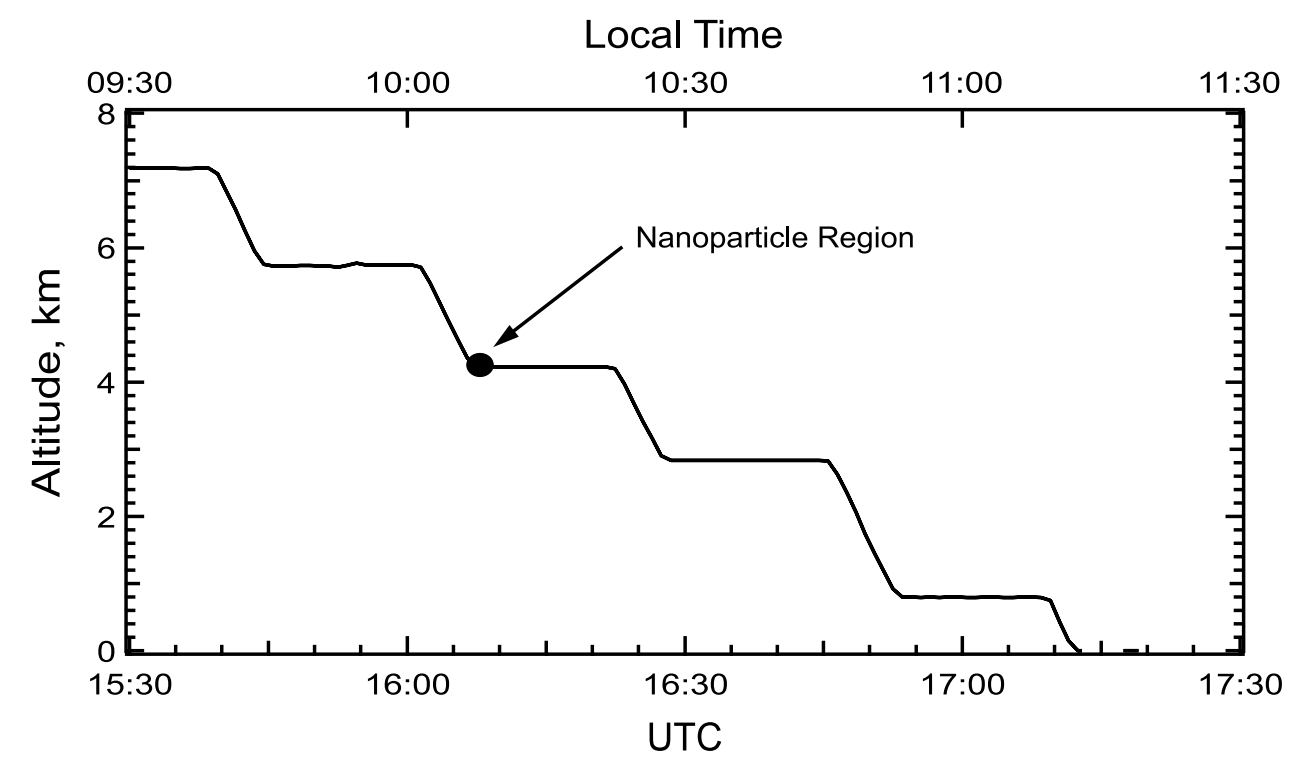

Figure 5. Stair-step flight pattern in region of $\mathrm{SO}_{2}$ plume. The region of high $3-4 \mathrm{~nm}$ particle concentrations is identified.

crossing Hudson Bay back to Churchill. The flight path is highlighted in Figure 1. In the first part of the return leg, shortly after the turn back toward Churchill, the aircraft decreased altitude in a stair step pattern, shown in Figure 5. Unusually high $\mathrm{SO}_{2}$ concentrations were detected over one horizontal step, covering a region approximately $240 \mathrm{~km}$ long. In this region the wind was almost directly from the West $\left(260^{\circ}-270^{\circ}\right.$ from $\left.\mathrm{N}\right)$ at a speed of about $20 \mathrm{~m} \mathrm{~s}^{-1}$. The vertical profile of this $\mathrm{SO}_{2}$ plume and associated species is shown in Figure 6.

[36] The temperature and relative humidity ( $\mathrm{RH})$ profiles in Figure 6 show a surface layer extending up to approximately $2 \mathrm{~km}$ altitude, and then consistently very dry at all altitudes above. This surface layer contained the highest fine (haze) aerosol concentrations in this region, in addition to highest fine sulfate (not plotted). The $\mathrm{SO}_{2}$ vertical profile shows that greatly enhanced concentrations were found above the surface layer, between approximately 3 to $5-\mathrm{km}$ altitude with a peak between 4 and $5 \mathrm{~km}$. $\mathrm{H}_{2} \mathrm{SO}_{4}$ concentrations were also higher in the 3 to $5-\mathrm{km}$ region, consistent with expectations of $\mathrm{H}_{2} \mathrm{SO}_{4}$ production from $\mathrm{SO}_{2}$. Although ultrafine condensation nuclei concentrations were also high, 3-4 nm particles were only detected in a narrow altitude range at approximately $4.2 \mathrm{~km}$. This narrow band is within the region of highest $\mathrm{SO}_{2}$ and $\mathrm{H}_{2} \mathrm{SO}_{4}$. Assuming the conditions under which nucleation occurred were somewhat similar to those observed in the $3-4 \mathrm{~nm}$ particle region, especially for the longer lived species like $\mathrm{SO}_{2}$, the correlation of 3-4 nm particles with $\mathrm{SO}_{2}$ and $\mathrm{H}_{2} \mathrm{SO}_{4}$ suggests the latter was a nucleation precursor. However, at a lower altitude of $2.8 \mathrm{~km}$, similar $\mathrm{H}_{2} \mathrm{SO}_{4}$ concentrations were measured, but in this case $3-4 \mathrm{~nm}$ particle concentrations were near zero. Classical nucleation theory predicts that nucleation rates depend on the degree of vapor saturation [e.g., Wilemski, 1984]. A measure of $\mathrm{H}_{2} \mathrm{SO}_{4}$ vapor saturation is the sulfuric relative acidity (RA). RA is calculated from the measured $\mathrm{H}_{2} \mathrm{SO}_{4}$ concentration, (this includes all monoacid hydrates), divided by the saturation concentration of pure acid over a flat surface, given as the partial pressure in atmospheres $(p)$ by Ayers et al. [1980] as

$$
\ln p=-\frac{10156}{T}+16.259,
$$

where $T$ is the absolute temperature. The vertical variation of RA, shown in Figure 5, indicates that highest sulfuric RA is associated with the region of 3-4 $\mathrm{nm}$ particles.

[37] The band of 3-4 $\mathrm{nm}$ particles may have resulted from nucleation in a very narrow region in the plume, possibly near the plume upper edge. Lack of 3-4 nm particles within other regions of the plume, yet elevated ultrafine condensation nuclei, may indicate that in these regions the aerosol was more aged. Nucleation may have occurred at a greater time prior and the newly formed particles grew past the 3-4 nm range resulting in low 3$4 \mathrm{~nm}$ and high ultrafine condensation nuclei concentrations.

[38] Although nucleation appears to have involved $\mathrm{H}_{2} \mathrm{SO}_{4}$, the actual mechanism is unclear, in part due to uncertainties as to whether nucleation had recently occurred or we were only detecting the remnants of an event that had occurred under different conditions (e.g., higher $\mathrm{H}_{2} \mathrm{SO}_{4}$ concentrations). The odd feature of this event is that it occurred under an extremely low $\mathrm{RH}$ of about $5 \%$. There is a positive, highly non-linear relation between $\mathrm{RH}$ and predicted nucleation rates for binary $\mathrm{H}_{2} \mathrm{SO}_{4}-\mathrm{H}_{2} \mathrm{O}$ nucleation. Experimental results of Ball et al. [1999] show that at these relative humidities, RAs on the order of 0.3 are necessary for the onset of nucleation (rate of 1 particle $\mathrm{cm}^{-3} \mathrm{~s}^{-1}$ ), much higher than the measured RA of 0.026 in the 3-4 nm particle zone. Note that these experiments were preformed at temperatures of $22^{\circ} \mathrm{C}$. Ambient temperatures in this case were $-30^{\circ} \mathrm{C}$. Although binary theory suggests that nucleation rates as a function of relative humidity and acidity are fairly insensitive to temperature as RH becomes low [Kulmala et al., 1998; Wilemski, 1984], the lack of experimental or model data at such low temperatures adds 


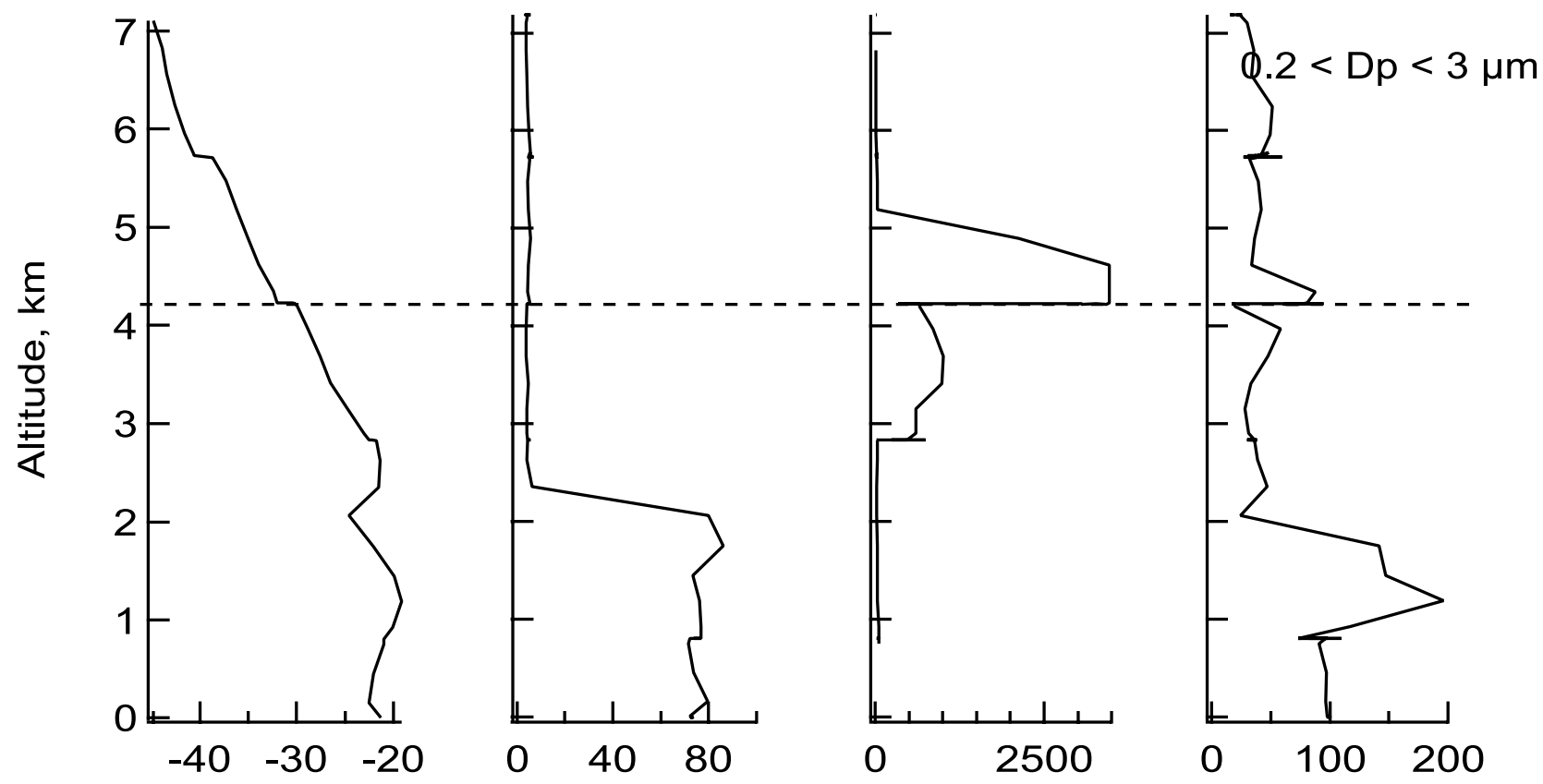

Temperature, ${ }^{\circ} \mathrm{C} \quad$ Relative Humidity, $\% \quad \mathrm{SO}_{2}$, pptv Fine Partilces, $\mathrm{cm}^{-3}$

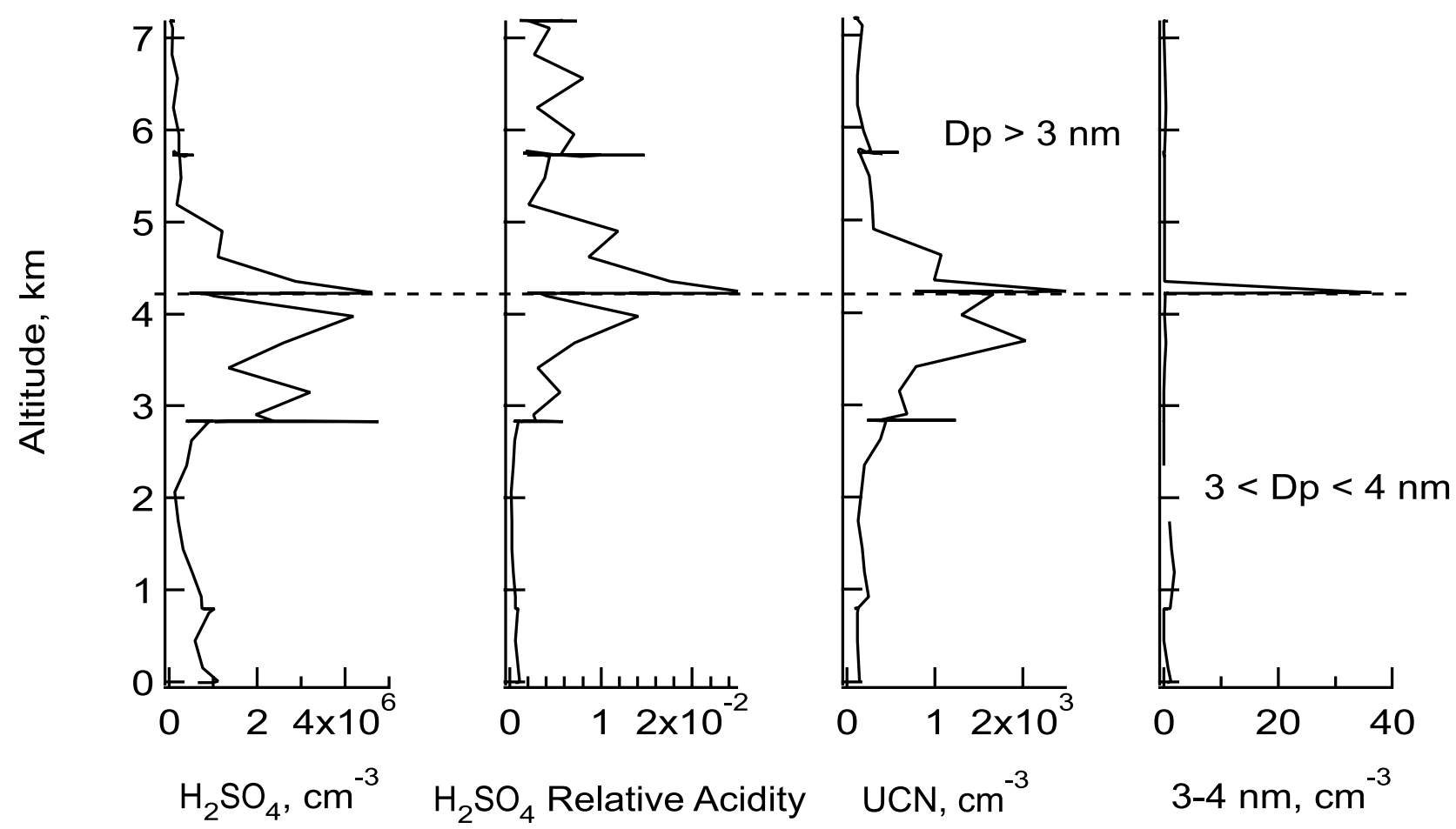

Figure 6. Vertical profiles of various species measured in the vicinity of the $\mathrm{SO}_{2}$ plume recorded during the stair-step flight path shown in Figure 5. Note the presence of high fine particle concentrations in the surface layer indicative of haze. The $\mathrm{SO}_{2}$ plume was situated above this layer and contained high $\mathrm{H}_{2} \mathrm{SO}_{4}$ and UCN concentrations but low fine aerosols suggesting most gas-to-particle conversion in this case was due to new particle formation. However, evidence for recent new particle formation, based on 3-4 nm particle concentrations, was only detected at the top of the layer. 
considerable uncertainty to this comparison. It is possible that the $\mathrm{H}_{2} \mathrm{SO}_{4}$, and thus RA, were much higher when these 3-4 $\mathrm{nm}$ particle were formed.

[39] Other nucleation mechanisms are possible, but not explored due to lack of data on possible precursor gases. Additional processes or nucleation precursors not measured, but uniquely present in this case may have played a role since RAs of even higher values than those recorded in this case were observed at higher altitudes (colder temperatures) during TOPSE, but lacked any evidence for particle formation.

[40] The source of the $\mathrm{SO}_{2}$ in this unique event has not been determined. Ten-day back trajectories suggest that the atmosphere was vertically stratified in this region since trajectories at slightly differing altitudes tended not to diverge or cross during a 10-day period. The back trajectories also suggest the air had been caught up in the polar vortex circling the pole and approaching the measurement region from over western Canada. Gaseous hydrocarbon tracers for anthropogenic sources, such as propane $\left(\mathrm{C}_{3} \mathrm{H}_{8}\right)$ and pentane $\left(\mathrm{C}_{5} \mathrm{H}_{12}\right)$, were not higher in the plume. Nor was $\mathrm{O}_{3}, \mathrm{CO}$, or NOy. Thus the plume does not appear to be anthropogenic in origin. Dimethyl sulfide (DMS) concentrations were below the detection limit of $1 \mathrm{pptv}$ [Simpson et al., 2001] for this flight suggesting that oceanic $\mathrm{SO}_{2}$ sources are unlikely. The exact source is unknown.

[41] An interesting feature of this event is that it places in perspective what conditions are required for nucleation in the TOPSE measurement domain (at least at higher altitudes where relative humidity is low). Since nucleation may have occurred sometime prior to the observations, and because $\mathrm{SO}_{2}$ concentrations tend to vary less in time than $\mathrm{H}_{2} \mathrm{SO}_{4}$, the concentrations of $\mathrm{SO}_{2}$ associated with this event may be more indicative of conditions necessary for nucleation in this region. Because this event was brought about by such a large $\mathrm{SO}_{2}$ perturbation from typical conditions, it supports our view that during TOPSE there was very little in situ particle production via large events.

[42] Finally, it should be pointed out that previous work has shown that nucleation in the free troposphere is often associated with regions of cloud venting [e.g., Perry and Hobbs, 1994]. In this study the near cloud fields were not systematically investigated and the role of particle formation associated with Arctic clouds is not investigated here.

\section{Conclusions}

[43] Latitudinal and temporal trends in $\mathrm{SO}_{2}, \mathrm{H}_{2} \mathrm{SO}_{2}$, ultrafine condensation nuclei (UNC), 3-4 nm particles, and fine particles are investigated for latitudes greater than $60^{\circ} \mathrm{N}$. Although concentrations are enhanced in the vicinity of populated areas, generally little evidence for uniform changes in concentration were observed for latitudes between 60 and $85^{\circ} \mathrm{N}$, except possibly for fine particles ( 0.2 to $3 \mu \mathrm{m}$ diameter). These particles can produce the socalled Arctic Haze, and appear to increase with latitude. Temporal trends investigated at three different altitudes, $(0$ to 2,2 to 5,5 to $8 \mathrm{~km}$ ) from February to May showed that with the exception of the 3-4 $\mathrm{nm}$ particles and ultrafine condensation nuclei, all species concentrations were highest near the surface. $\mathrm{SO}_{2}$ tended to increase till the end of March and then decline. $\mathrm{H}_{2} \mathrm{SO}_{4}$ near the surface tended to increase to the end of April, and then dropped off. Fine sulfate aerosol followed a similar trend as $\mathrm{H}_{2} \mathrm{SO}_{4}$ at all altitudes. Fine particle number concentrations steadily increased throughout the TOPSE experiment. These observations are consistent with increasing photochemical production of $\mathrm{H}_{2} \mathrm{SO}_{4}$ and fine particle numbers and mass, and a lack of increasing in situ new particle production as the Arctic spring progressed.

[44] Throughout the study, in all latitude ranges, plumes of various species were frequently intercepted. This included haze layers and also regions of high $\mathrm{SO}_{2}$, $\mathrm{H}_{2} \mathrm{SO}_{4}$, and ultrafine condensation nuclei not associated with haze (fine particles). Evidence for significant new particle formation by homogeneous nucleation during the TOPSE study was only detected in the upper edges of a plume consisting of unusually high $\mathrm{SO}_{2}$ concentrations. Peak $\mathrm{SO}_{2}$ concentrations were $3.46 \mathrm{ppbv}$, two orders of magnitude higher than those typically recorded during the study. Because nucleation was only detected in this singular event, it suggests that conditions encountered during the TOPSE experiment were generally not conducive to new particle formation, and that most photochemically produced gaseous species participating in gas-to-particle conversion following polar sunrise were absorbed by the preexisting aerosol. Because current aerosol instruments cannot detected freshly formed particles, and particle growth processes in the Arctic tend to be slow, an in situ low production rate of new particles during the TOPSE experiment cannot be ruled out.

[45] Acknowledgments. The authors gratefully acknowledge financial support from the National Science Foundation through Grant No. OOP9908278. We also thank the staff of the Research Aviation Facility (RAF) of the National Center for Atmospheric Research (NCAR).

\section{References}

Ayers, G. P., R. W. Gillett, and J. L. Gras, On the vapor pressure of sulfuric acid, Geophys. Res. Lett., 7, 433-436, 1980.

Ball, S. M., D. R. Hanson, F. L. Eisele, and P. H. McMurry, Laboratory studies of particle nucleation: Initial results for $\mathrm{H}_{2} \mathrm{SO}_{4}, \mathrm{H}_{2} \mathrm{O}$, and $\mathrm{NH}_{3}$ vapors, J. Geophys. Res., 104, 23,709-23,718, 1999.

Barrie, L., Arctic air pollution: An overview of current knowledge, Atmos. Envir., 20, 643-663, 1986.

Brock, C. A., L. F. Radke, J. H. Lyons, and P. B. Hobbs, Actic hazes in summer over Greenland and the North American Arcitc: I Incidence and origins, J. Atmos. Chem., 9, 129-148, 1989.

Cofer, W. R., V. G. Collins, and R. W. Talbot, Improved aqueous scrubber for collection of soluble atmospheric trace gases, Environ. Sci. Technol., 19, 557-560, 1985.

Covert, D. S., A. Wiedensohler, P. Aalto, J. Heintzenberg, P. McMurry, and C. Leck, Aerosol number, size distributions from 3 to $500 \mathrm{~nm}$ diameter in the summer Arctic marine boundary layer, Tellus Ser. B, 48B, 197-212, 1996.

Dick, W. D., P. H. McMurry, R. J. Weber, and F. R. Quant, White light detection for nanoparticle sizing with the new TSI ultrafine condensation particle counter, J. Nanoparticle Res., 2, 85-90, 2000.

Dreiling, V., and B. Friederich, Spatial distribution of the arctic haze aerosol size distribution in western and eastern Arctic, Atmos. Res., 44, 133-152, 1997.

Eisele, F. L., Natural and anthropogenic negative ions in the troposphere, J. Geophys. Res., 94, 2183-2196, 1989.

Eisele, F. L., and D. J. Tanner, Measurement of the gas phase concentrations of $\mathrm{H}_{2} \mathrm{SO}_{4}$ and Methane Sulfonic acid and estimates of $\mathrm{H}_{2} \mathrm{SO}_{4}$ production and loss in the atmosphere, J. Geophys. Res., 98, 9001-9010, 1993.

Heintzenberg, J., Arctic Haze: Air pollution in polar regions, Ambio, 18, $50-55,1989$.

Kulmala, M., A. Laaksonen, and L. Pirjola, Parameterizations for sulfuric acid/water nucleation rates, J. Geophys. Res., 103, 8301-8307, 1998.

Marti, J. J., R. J. Weber, M. T. Saros, J. G. Vasiliou, and P. H. McMurry, Technical Note: Modification of the TSI 3025 condensation particle 
counter for pulse height analysis, Aerosol Sci. Technol., 25, 214-218, 1996.

Pacyna, J. M., The origin of Arctic air-pollutants - lessons learned and future-research, Sci. Total Environ., 161, 39-53, 1995.

Perry, K. D., and P. V. Hobbs, Further evidence for particle nucleation in clear air adjacent to marine cumulus clouds, J. Geophys. Res., 99, 22,803-22,818, 1994.

Pirjola, L., A. Laaksonen, P. Aalto, and M. Kulmala, Sulfate aerosol formation in the Arctic boundary layer, J. Geophys. Res., 103, 8309-8321, 1998.

Polissar, A. V., P. K. Hopke, W. C. Malm, and J. F. Sisler, Atmsopheric aerosol over Alaska, 1, Spatial and seasonal variability, J. Geophys. Res., 103, 19,035-19,044, 1998.

Polissar, A. V., P. K. Hopke, P. Paatero, Y. J. Kaufmann, D. K. Hall, B. A. Bodhaine, E. G. Dutton, and J. M. Harris, The aerosol at Barrow, Alaska: Long-term trends and source locations, Atmos. Environ., 33, 2441-2458, 1999.

Radke, L. F., J. H. Lyons, D. A. Hegg, and P. V. Hobbs, Airborne observations of Arctic aeorosols, I, Characteristics of Arctic haze, Geophys. Res. Lett., 11, 369-372, 1984.

Rahn, K., Relative importance of North America and Eurasia as sources of Arctic aerosols, Atmos. Environ., 15, 1447-1456, 1981.

Saros, M. T., R. J. Weber, J. J. Marti, and P. H. McMurry, Ultrafine aerosol measurement using a condensation nucleus counter with pulse height analysis, Aerosol Sci. Technol., 25, 200-213, 1996.

Scheuer, E., R. W. Talbot, J. E. Dibb, G. K. Seid, L. DeBell, and B. Lefer, Seasonal distributions of fine aerosol sulfate in the North American Arctic basin during TOPSE, J. Geophys. Res, doi:10.1029/2001JD001364, 2002.

Shaw, G. E., Aerosol measurements in Central Alaska 1982-1984, Atmos. Environ., 19, 2013-2025, 1985.

Shaw, G. E., Production of Condensation Nuclei in Clean air by Nucleation of $\mathrm{H}_{2} \mathrm{SO}_{4}$, Atmos. Environ., V23, 2841-2846, 1989.

Shaw, G. E., The Arctic haze phenomenon, Bull. Am. Meteorol. Soc., 76 , 2403-2413, 1995.

Simpson, I. J., J. J. Colman, A. L. Swanson, A. R. Bandy, D. C. Thornton, D. R. Blake, and F. S. Rowland, Aircraft measurements of dimethyl sulfide (DMS) using a whole air sampling technique, J. Atmos. Chem., 39, 191-213, 2001

Sirois, A., and L. A. Barrie, Arctic lower tropospheric aerosol trends and composition at Alert, Canada: 1985-1995, J. Geophys. Res., 104, 11,599-11,618, 1999.

Weber, R. J., P. H. McMurry, F. L. Eisele, and D. J. Tanner, Measurement of expected nucleation precursor species and 3 to $500 \mathrm{~nm}$ diameter particles at Mauna Loa Observatory, Hawaii, J. Atmos. Sci., 52, 2242-2257, 1995.

Weber, R. J., J. J. Marti, P. H. McMurry, F. L. Eisele, D. J. Tanner, and A. Jefferson, Measured atmospheric new particle formation rates: Implications for nucleation mechanisms, Chem. Eng. Comm., 151, 53-64, 1996.

Weber, R. J., J. J. Marti, P. H. McMurry, F. L. Eisele, D. J. Tanner, and A. Jefferson, Measurements of new particle formation and ultrafine par- ticle growth rates at a clean continental site, J. Geophys. Res., 102, 4375-4385, 1997.

Weber, R. J., A. D. Clarke, M. Litchy, J. Li, G. Kok, R. D. Schillawski, and P. H. McMurry, Spurious aerosol measurements when sampling from aircraft in the vicinity of clouds, J. Geophys. Res., 103, 28,337-28,346, 1998 a.

Weber, R. J., P. H. McMurry, L. Mauldin, D. Tanner, F. Eisele, F. Brechtel, S. Kreidenweis, G. Kok, R. Schillawski, and D. Baumgardner, A study of new particle formation and growth involving biogenic trace gas species measured during ACE 1, J. Geophys. Res., 103, 16,385-16,396, 1998b.

Weber, R. J., M. Stolzenburg, S. Pandis, and P. H. McMurry, Inversion of UCNC pulse height distributions to obtain ultrafine $(\sim 3$ to $10 \mathrm{~nm})$ particle size distributions, J. Aerosol Sci., 29, 601-615, 1998c.

Weber, R. J., P. H. McMurry, T. S. Bates, D. S. Covert, F. J. Brechtel, and G. L. Kok, Intercomparison of airborne and surface-based measurements of condensation nuclei in the remote marine troposphere measured during ACE 1, J. Geophys. Res., 104, 21,673-21,683, 1999a.

Weber, R. J., P. H. McMurry, L. Mauldin, D. Tanner, F. Eisele, A. Clarke, and V. N. Kapustin, New particle production in the remote troposphere: A comparison of observations at various sites, Geophys. Res. Lett., 26, 307-310, 1999b.

Weber, R. J., G. Chen, D. D. Davis, R. L. Mauldin, D. J. Tanner, F. L. Eisele, A. D. Clarke, D. C. Thorton, and A. R. Bandy, Measurements of enhanced $\mathrm{H}_{2} \mathrm{SO}_{4}$ and $3-4 \mathrm{~nm}$ particles near a frontal cloud during ACE 1, J. Geophys. Res., 106, 24,107-24,118, 2001a.

Weber, R. J., V. K. K. Moore, A. Clarke, R. L. Mauldin, E. Kosciuch, C. Cantrell, F. Eisele, B. Anderson, and L. Thornhill, Nucleation in the equatorial pacific during PEM Tropics B: Enhanced boundary layer $\mathrm{H}_{2} \mathrm{SO}_{4}$ but no particle production, J. Geophys. Res, doi:10.1209/2002JD002239, in press, $2001 \mathrm{~b}$.

Wiedensohler, A., D. S. Covert, E. Swietlicki, P. Aalto, J. Heintzenberg, and C. Leck, Occurrence of an ultrafine particle mode less than $20 \mathrm{~nm}$ in diameter in the marine boundary layer during Arctic summer and autumn, Tellus Ser. B, 48, 213-222, 1996.

Wilemski, G., Composition of the critical nucleus in multicomponent vapor nucleation, J. Chem. Phys., 80, 1370-1372, 1984.

Xie, Y. L., P. K. Hopke, P. Paatero, L. A. Barrie, and S. M. Li, Identification of source nature and seasonal variations of Arctic aerosol by the multilinear engine, Atmos. Environ., 33, 2549-2562, 1999.

C. Cantrell, F. Eisele, E. Kosciuch, and R. L. Mauldin, National Center for Atmospheric Research, P. O. Box 3000, Boulder, CO 80307, USA

L. DeBell, J. E. Dibb, E. Scheuer, G. K. Seid, and R. W. Talbot, Institute for the Study of Earth, Oceans, and Space, University of New Hampshire, Morse Hall, Durham, NH 03824, USA.

D. Orsini, B. Wang, and R. J. Weber, School of Earth and Atmospheric Sciences, Georgia Institute of Technology, 221 Bobby Dodd Way, Atlanta, GA 30332, USA. (rweber@eas.gatech.edu) 